ISSN 0258-7122

Bangladesh J. Agril. Res. 37(2): 263-269, June 2012

\title{
PHYSIO-MORPHOLOGICAL FEATURES OF CHILLI ACCESSIONS UNDER MOISTURE STRESS CONDITIONS
}

\author{
M. A. I. KHAN ${ }^{1}$, M. A. HOQUE ${ }^{2}$, A. M. FAROOQUE ${ }^{3}$ \\ U. HABIBA ${ }^{4}$ AND M. A. RAHIM ${ }^{5}$
}

\begin{abstract}
An experiment was carried out at the Bangladesh Agricultural University, Mymensingh during October 2005 to March 2007 to study the effect of different soil water levels on the physio-morphological features of ten Chilli (Capsicum annuum L.) accessions viz. C-0277, C-0297, BM-1, C-0100, BM-2, C-0265, C0272, C-0275, BM-3, and C-0271. The experiment was set up in pots under glasshouse condition. The water treatments were applied at 4 vegetative growth stages following withholding method (crude method) starting from 25 days after sowing and thereafter at every 7 days interval until final stage. The water treatments applied were $\mathrm{W}_{1}=$ watering once a day; $\mathrm{W}_{2}=$ watering at 4 days interval; $\mathrm{W}_{3}=$ watering at 8 days of interval, and $\mathrm{W}_{0}=$ no watering. Moisture capacity of polybag (analogous to field capacity) was determined by subtracting leached water from the original amount of water applied. In most of the parameters studied, $\mathrm{W}_{2}$ gave the highest value, $\mathrm{W}_{1}$ and $\mathrm{W}_{0}$ gave the lowest, while $\mathrm{W}_{3}$ in between. Only a slight deviation was noticed in case of root volume and root dry weight, where $\mathrm{W}_{0}$ produced the $2^{\text {nd }}$ highest and highest values, respectively. The effects of different water treatments on all the growth parameters studied was significant in case of all accessions and growth stages. The accessions C-0271, C-0277, BM-1, and C-0297 produced higher dry matter.
\end{abstract}

Keywords: Physio-morphological, chilli accessions, stress condition.

\section{Introduction}

Chilli under the genus Capsicum belonging to the family Solanaceae, is a spice crop which yields different types of edible pods under two commercial species, namely Capsicum annum L. and Capsicum fruitescens $L$. Chilli is widely grown in various parts of Bangladesh mostly in Rabi season and some short duration early kharif chilli cutivars are also cultivated in Bangladesh. An ideal medium for growing chilli is a light loamy soil rich in lime (Muthukrishnan et al., 1983). Acidic and alkaline soils are not suitable for chilli growing (Kaliappan and Rajagopal, 1970). Adequate water is indispensable for vital function of plants. Water deficit often limits plant growth and development. Water stress during

${ }^{1}$ Chief Scientific Officer, Horticulture Research Centre, (HRC), Bangladesh Agricultural Research Institute (BARI), Gazipur, ${ }^{2}$ Associate Professor, Department of Horticulture, Bangabandhu Sheikh Mujibur Rahman Agricultural University (BSMRAU), Gazipur1706, ${ }^{3}$ Sher-e-Bangla Agricultural University (SAU), Dhaka, ${ }^{4}$ Lecturer, Deptt. of Botany, Shahid Smriti Govt. College, Muktagacha, Mymensingh, ${ }^{5}$ Professor, Deptt. of Horticulture, Bangladesh Agricultural university (BAU), Mymensingh, Bangladesh. 
vegetative stage reduces the leaf area index (LAI) and biomass production. Young chilli seedlings cannot withstand either deficit or excess soil moisture. Older seedlings and plants, however, can withstand deficit or excess water to certain extent (Ayoub, 1986; Hedge, 1989). To improve the productivity of crops under an environment in which water deficiency or excess water condition frequently occurs, proper water management is necessary (Hale and Orcutt, 1987; Hurd, 1975; Quisenberry, 1982). Lots of research reports are available on chilli focussing various areas of investigations, such as photosynthesis, assimilate partitioning, hormonal response on growth and yield, yield trial, genetics, cytology, breeding for better varieties, light and salt stress, etc. But effect of water stress on chilli has been reported by only a few researchers (Katerji et al., 1993; Techawongstein et al., 1992) in abroad only. Considering the above facts, the present piece of research work was undertaken to study the physiomorphological features of 10 local accessions of chilli by allowing them to grow in excess and deficit soil moisture conditions.

\section{Materials and Method}

The present investigation was carried out under glasshouse in Polybags at Bangladesh Agricultural University, Mymensingh during 21 October 2005 to 18 March 2007. Ten accessions of chilli, viz. C-0277 $=V_{1}$, C-C0297 $=V_{2}$, BM-1= $\mathrm{V}_{3}, \mathrm{C}-0100=\mathrm{V}_{4}, \mathrm{BM}-2=\mathrm{V}_{5}, \mathrm{C}-0265=\mathrm{V}_{6}, \mathrm{C}-0272=\mathrm{V}_{7}, \mathrm{C}-0275=\mathrm{V}_{8}, \mathrm{BM}-3=\mathrm{V}_{9}$, and $\mathrm{C}-0271=\mathrm{V}_{10}$, were included for the study. The growing medium was prepared with the ratio of 60:30:10 for fine river sand, soil and rotten cowdung, respectively, and put in $20 \times 12 \mathrm{~cm}$ size polybag weighing 5kg each. Polybag capacity (analogous to field capacity) of the growing medium in the specific polybag size and weight used in the experiment was determined so as to maintain optimum and uniform moisture levels particularly at the time of seed sowing. To determine polybag capacity, randomly selected polybags were evenly watered until water leaked from the bottom. After eight hours of drainage, sand or compost samples were collected in soil cores and oven dried at $80^{\circ} \mathrm{C}$ for 72 hours. The moisture contents of the samples were determined and used in determining the polybag capacity of the pre weighed growing media for glasshouse experiment.

Different treatments were imposed by withholding water for varying intervals according to the moisture levels desired in the experiment. Fertilizers were applied in each bag after $10-15$ days of treatment imposition, on a day when all the treatments received water. Each irrigation aimed to return the bag to its capacity level so that the whole of the growing medium in each bag of each treatment received optimum moisture. For treatment application an estimate was made by randomly selecting three bags of each treatment and watering them until leaked from the bottom. After two hours, the leached water was measured and 
subtracted from the original volume applied and considered it as the optimum bag capacity and this volume was given to all other bags of the same treatment. This method of water treatment application was followed by Hamid (1993).

\section{Vegetative growth stages and application of water treatments}

Water treatments were imposed in 4 stages of vegetative growth each having 7 days of span. Upto 31 days of sowing, it was considered as lst stage and thereafter every 7 days for each stage. The stages were denoted as $S_{1}=25-31$ days (after seed sowing), $S_{2}=32-38$ days, $S_{3}=39-45$ days and $S_{4}=46-52$ days. Water treatment was started on 14 November 2005 when most of the plants possessed at least 2-4 visible leaves. The watering treatments were $\mathrm{W}_{1}=$ watering once a day, $\mathrm{W}_{2}=$ watering at 4days interval, $\mathrm{W}_{3}=$ watering at 8 days interval and $\mathrm{Wo}=$ no watering (control).

\section{Experimental design and seed sowing}

Split-split plot design was followed having 3 replications. Six seeds per bag were sown on 21 October 2005 and the germinated plants were thinned to 1 in each bag before imposition of moisture (water) treatments.

\section{Results and Discussion}

The single effect of the factors, chilli accessions, vegetative growth stage and water treatments are shown in Table $1,2 \& 3$, respectively. The accessions of chilli included in this experiment have been found with significant differences among themselves on the physio-morphological characters (Table 1).

The number of leaves and leaf area per plant have been found to be smaller in lower moisture treatments like $\mathrm{W}_{3}$ and $\mathrm{W}_{0}$ (Table 3). Horton et al. (1982) reported fewer leaves per chilli plant with the drier treatments. Smaller leaf area with drier treatment was also observed by Beese et al. (1982) in different chilli varieties. So, the present findings on the number of leaves and leaf area are in agreement with those findings. The plant height, number of internodes, root length, root volume, leaf, stem and root dry weight were also affected by the water stress treatments (Table 3). Techawongstein et al. (1992) observed suppression of plant height due to water stress in chilli. So, the number of internodes was reduced due to suppression in stem elongation (plant height) in the present investigation (Table 3). Beese et al. (1982) reported reduction in final yield of above and below ground plant parts in chilli due to moisture stress effect. Several workers also found lower values of many growth parameters including dry weight of different plant parts as a result of water stress (Ayob, 1986; Beese and Moshrefi, 1985; Hedge, 1989; Smittle et al., 1994). The present findings of lower values of many plant parts and dry weights of leaf, stem, and root under water stress treatments reflected the reports of different authors mentioned above. The shoot and total dry weight reduction under moisture stress situation in this study was in fact due to the reduction in values of growth relating parameters like leaf, stem and root of chilli plants. 
Table 1. Effect of cultivars on the physio-morphological characters of chilli.

\begin{tabular}{cccccccccccc}
\hline $\mathrm{V}$ & 1 & 2 & 3 & 4 & 5 & 6 & 7 & 8 & 9 & 10 & 11 \\
\hline $\mathrm{V}_{1}$ & 18.29 & 123.90 & 21.40 & 10.26 & 1319.61 & 1.22 & 0.268 & 0.196 & 0.160 & 0.463 & 0.623 \\
$\mathrm{~V}_{2}$ & 16.72 & 104.49 & 19.30 & 9.34 & 555.00 & 0.66 & 0.212 & 0.152 & 0.100 & 0.364 & 0.464 \\
$\mathrm{~V}_{3}$ & 19.40 & 106.48 & 20.76 & 9.49 & 534.41 & 0.56 & 0.209 & 0.165 & 0.092 & 0.374 & 0.466 \\
$\mathrm{~V}_{4}$ & 16.63 & 92.62 & 20.12 & 10.88 & 703.46 & 0.48 & 0.175 & 0.140 & 0.103 & 0.315 & 0.419 \\
$\mathrm{~V}_{5}$ & 14.16 & 73.32 & 19.06 & 9.17 & 615.62 & 0.52 & 0.147 & 0.108 & 0.099 & 0.258 & 0.357 \\
$\mathrm{~V}_{6}$ & 12.76 & 72.57 & 18.47 & 9.51 & 705.89 & 0.63 & 0.179 & 0.109 & 0.091 & 0.288 & 0.379 \\
$\mathrm{~V}_{7}$ & 13.84 & 68.69 & 18.35 & 9.64 & 341.20 & 0.30 & 0.128 & 0.100 & 0.055 & 0.228 & 0.283 \\
$\mathrm{~V}_{8}$ & 13.59 & 63.52 & 17.27 & 8.78 & 366.64 & 0.40 & 0.119 & 0.090 & 0.060 & 0.206 & 0.266 \\
$\mathrm{~V}_{9}$ & 14.38 & 88.46 & 18.70 & 10.87 & 336.36 & 0.65 & 0.205 & 0.106 & 0.102 & 0.310 & 0.412 \\
$\mathrm{~V}_{10}$ & 15.35 & 124.70 & 22.72 & 9.49 & 1147.55 & 0.98 & 0.245 & 0.216 & 0.130 & 0.461 & 0.591 \\
\hline $\mathrm{LSD}$ & 0.362 & 2.582 & 0.487 & 0.309 & 12.921 & 0.046 & 0.013 & 0.013 & 0.004 & 0.013 & 0.013 \\
\hline $\mathrm{CV}$ & 5.84 & 7.02 & 6.20 & 7.94 & 4.66 & 17.66 & 12.35 & 16.88 & 11.79 & 10.25 & 8.39 \\
\hline
\end{tabular}

$\mathrm{V}=$ Cultivar, LSD at 0.05 level, CV in \%, 1= No. of leaves per plant $2=$ Leaf area per plant $\left(\mathrm{cm}^{2}\right), 3=$ plant height $(\mathrm{cm}), 4=$ No. of Internodes, 5 = Root length $(\mathrm{cm}), 6=$ Root volume $(\mathrm{ml}), 7$ = Leaf dry weight $(\mathrm{g}), 8=$ Stem dry weight $(\mathrm{g}), 9=$ Root dry weight $(\mathrm{g}), 10=$ Shoot dry weight $(\mathrm{g})$ and $11=$ Total dry weight $(\mathrm{g})$. 
Table 2. Effect of growth stages on the physio-morphological characters of chilli.

\begin{tabular}{cccccccccccccc}
\hline $\mathrm{S}$ & 1 & 2 & 3 & 4 & 5 & 6 & 7 & 8 & 9 & 10 \\
\hline $\mathrm{S}_{1}$ & 7.90 & 31.91 & 11.53 & 6.30 & 34.10 & 0.23 & 0.054 & 0.026 & 0.013 & 0.08 & 0.093 \\
$\mathrm{~S}_{2}$ & 11.81 & 56.54 & 16.57 & 8.55 & 220.07 & 0.26 & 0.124 & 0.085 & 0.036 & 0.208 & 0.244 \\
$\mathrm{~S}_{3}$ & 19.12 & 117.78 & 22.05 & 10.65 & 473.60 & 0.47 & 0.223 & 0.157 & 0.131 & 0.382 & 0.513 \\
$\mathrm{~S}_{4}$ & 23.23 & 161.27 & 28.31 & 13.48 & 2042.53 & 1.60 & 0.353 & 0.285 & 0.217 & 0.637 & 0.854 \\
\hline $\mathrm{LSD}$ & 0.258 & 3.145 & 0.477 & 0.242 & 4.196 & 0.96 & 0.002 & 0.008 & 0.003 & 0.008 & 0.011 \\
$\mathrm{CV}$ & 5.84 & 7.02 & 6.20 & 7.94 & 4.66 & 17.66 & 12.35 & 16.88 & 11.79 & 10.25 & 8.39 \\
\hline
\end{tabular}

$\mathrm{S}=$ Growth stage, LSD at 0.05 level, CV in \%, $1=$ No. of leaves per plant, $2=$ leaf area per plant $\left(\mathrm{cm}^{2}\right), 3=$ Plant height $(\mathrm{cm}), 4=$ No. of Internodes, 5 = Root length $(\mathrm{cm}), 6=$ Root volume $(\mathrm{ml}), 7$ = leaf dry weight $(\mathrm{g}), 8=$ Stem dry weight $(\mathrm{g}), 9=$ Root dry weight $(\mathrm{g}), 10=$ Shoot dry weight (g) and 11 = Total dry weight (g).

Table 3. Effect of water treatments on the physio-morphological characters of chilli.

\begin{tabular}{ccccccccccccc}
\hline $\mathrm{T}$ & 1 & 2 & 3 & 4 & 5 & 6 & 7 & 8 & 9 & 10 & 11 \\
\hline $\mathrm{W}_{1}$ & 14.62 & 63.11 & 17.01 & 9.10 & 590.64 & 0.55 & 0.166 & 0.100 & 0.085 & 0.267 & 0.352 \\
$\mathrm{~W}_{2}$ & 19.31 & 123.06 & 23.36 & 10.68 & 814.25 & 0.73 & 0.256 & 0.1930 & 0.096 & 0.449 & 0.545 \\
$\mathrm{~W}_{3}$ & 15.07 & 97.96 & 19.85 & 10.27 & 778.69 & 0.63 & 0.209 & 0.136 & 0.105 & 0.345 & 0.451 \\
$\mathrm{~W}_{4}$ & 13.06 & 83.37 & 18.24 & 8.92 & 586.72 & 0.66 & 0.163 & 0.124 & 0.11 & 0.246 & 0.356 \\
\hline $\mathrm{LSD}$ & 0.257 & 2.061 & 0.369 & 0.233 & 14.81 & 0.034 & 0.003 & 0.008 & 0.003 & 0.008 & 0.011 \\
$\mathrm{CV}$ & 5.84 & 7.02 & 6.20 & 7.94 & 4.66 & 17.66 & 12.35 & 16.88 & 11.79 & 10.25 & 8.39 \\
\hline
\end{tabular}

$\mathrm{T}=$ Treatment, $\mathrm{W}=$ Water, $\mathrm{LSD}$ at 0.05 level, CV in \%, $1=$ No. of leaves per plant, $2=$ leaf area per plant $\left(\mathrm{cm}^{2}\right), 3=$ Plant height $(\mathrm{cm}), 4$ = No. of Internodes, 5 = Root length $(\mathrm{cm})$, $6=$ Root volume $(\mathrm{ml}), 7=$ leaf dry weight $(\mathrm{g}), 8=$ Stem weight $(\mathrm{g}), 9=$ Root dry weight $(\mathrm{g})$, $10=$ Shoot dry weight $(\mathrm{g})$ and $11=$ Total dry weight $(\mathrm{g})$. 
It was observed that all the studied parameters gradually produced higher values as the age of plants proceeded from $S_{1}$ to $S_{4}$ growth stages (Table 2). In later stages, most of the parameters including number of leaves and leaf area increased as more and more sun light interception occurred which accumulated increased $\mathrm{CO}_{2}$ assimilation. Ultimately quantity of dry matter production in different plant parts increased. The water treatments in combination with growth stages and chilli accessions also gave the similar trend as observed in single effects (Table 4). It is evident from the Table 4 that in combination with other factors like growth stages and accessions, the water treatments remained as the determining factor of the results. The domination of water treatments effects was proved true as the combination effects produced the same trend as that of single effects of water treatments.

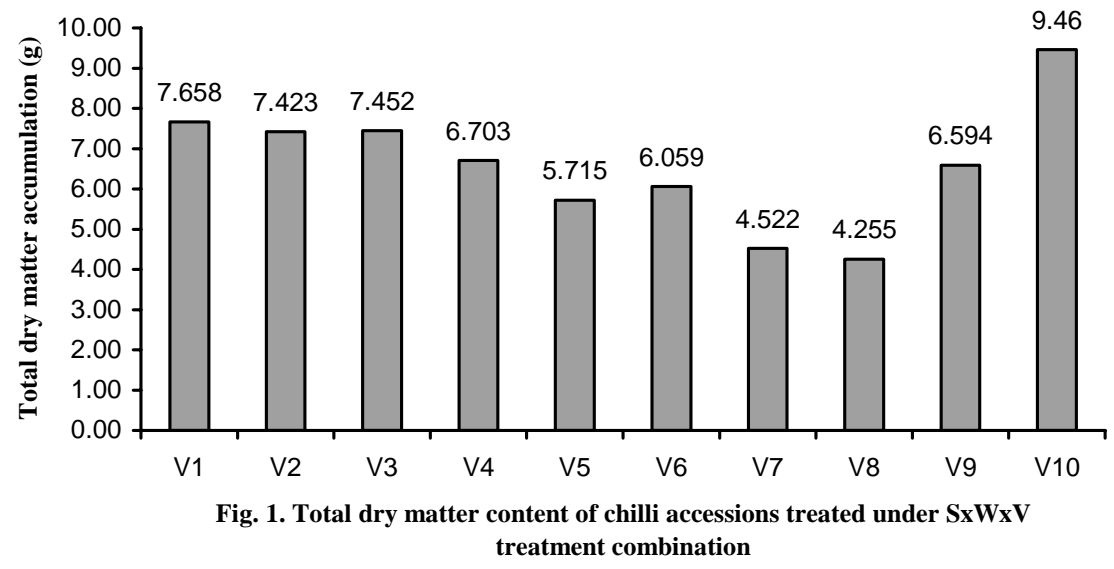

The accessions C-0271 $\left(\mathrm{V}_{10}\right)$ produced the highest dry matter $(9.46 \mathrm{~g})$ content followed by C-0277 (7.66g), BM-1 (7.45g) and C-0297 (7.42g); while C-0275 $\left(\mathrm{V}_{8}\right)$ produced the lowest $(4.255 \mathrm{~g})$ dry matter (Fig. 1) contents as combined effect of the three factors involved the present study. This was preliminary identification of the chilli accessions on the basis of dry matter contents produced under combined effect of different water treatments. The accessions with higher and lower dry matter contents were selected as the water stress tolerant and susceptible ones, respectively. Hsiao and Acevedo (1974) had the opinion that the yield and dry matter content might have little effect if the water stress was not severe even though it would be sufficient to reduce enlargement. So, it is most likely that the accessions with lower dry matter content in this case are susceptible to water stress and on the other hand, accessions with higher dry matter content are tolerant to water stress. 


\section{Conclusion}

On overall consideration, it can be concluded that the accessions C-0271, C0277, BM-1 and C-0297 may be utilized as water stress tolerant in chilli.

\section{References}

Ayob, K. 1986. Effect of available soil moisture on the yield of chilli (Capsicum annuum). Techonlogy Sayur Sayura 2: 57-59.

Beese, F., R. Horton and P. J. Wierenga. 1982. Growth and yield response of chilli pepper to trickle irrigation. Agron. J. 74: 556-561.

Beese, F. and N. Moshrefi. 1985. Physiological reaction of chilli pepper to water and salt stress. Dripper Trickle Irrigation in Action 2: 646-651.

Hale, M. G. and D. M. Orcutt. 1987. The physiology of plants under stress. WileyInterSci., New York.

Hamid, M. A. 1993. Drought tolerance study in Vicia faba. A Ph. D. Thesis submitted to Wye College, London.

Hedge, D. M. 1989. Effect of soil moisture and nitrogen on plant water relations, mineral composition and productivity of bell pepper (Capsicum annum). Indian J. Agron. 34(1):30-34.

Hsiao, T. C. and E. Acevedo. 1974. Plant response to water use efficiency and drought resistance. Agric. Meteorol. 14:59-84.

Hurd, E. A. 1975. Phenotype and drought tolerance in wheat. In: J.F. Stone (ed.) Plant modification for more efficient water use. Elsever Pun., New York.

Horton, R., F. Beese and P.J. Wierenga. 1982. Physiological response of chilli pepper to trickle irrigation. Agron. J. 74: 357-555.

Kaliappan, R. and A. Rajagopal. 1970. Vegetable Crops in India. Naya Prokash, Calcutta.

Katerji. N., M. Mastrorilli and A. Hamdy. 1993. Effects of water stress at different growth stages on pepper yield. Acta Hort. 335.

Muthukrishnan, C.R., T. Thangaraj and R. Chatterjee. 1983. Vegetable Crops in India. Naya Prokash, Calcutta.

Quisenberry, J. E. 1982. Breeding for drought resistance and plant water use efficiency. In: M.N. Christaninson and C.F. Lewis (eds). Breeding for less favorable environments. Wiley-InterSci., New York.

Smittle, D.A., W.L. Dickens and J.R. Stansell. 1994. Irrigation regimes affect yield and water use by bell pepper. J. Amer. Soc. Hort. Sci. 119(5): 936-939.

Techawongstein, S., E. Nawata and S. Shigenaga. 1992. Effect of water strees at various stages of plant development on growth and yield of chilli pepper. Japan. J. Trop. Agr 536(1): 51-57. 